\title{
Histopathological spectrum of ovarian cyst in our rural area
}

\author{
Dost Mohamed Khan ${ }^{1}$, Abilash S.C ${ }^{2, *}$, Ravathisheree R ${ }^{3}$, Haritha R.S \\ ${ }^{1}$ Professor, ${ }^{2,3}$ Associate Professor, ${ }^{4}$ Postgraduate Student, Dept. of Pathology, Shri Sathya Sai Medical College \& Research \\ Institute, Kancheepuram, Tamil Nadu, India
}

*Corresponding Author:

Email: abey4aris@gmail.com

\begin{abstract}
Introduction: Ovarian cysts and tumors are the major health problem in women. Ovarian Cysts are the most prevalent pelvic mass and often associated with function disorders of menstruation which are mostly improved spontaneously. In some cases which are the result of cyst rupture, torsion or bleeding in to the cyst, laparotomy may be needed

Aim: The aim of this study is to highlight the histopathological study of ovarian cysts in rural area.

Materials and Methods: Hematoxylin and eosin stained slides of ovarian biopsies for 4 years were archived, scrutinized, and studied. Request forms were analyzed for clinical biodata and diagnosis, and data were analyzed with Statistical Package for Social Sciences (SPSS) version 21.

Results: Total number of 197 ovarian biopsies were reviewed. Out of which, 149 (75.6\%) of nonneoplastic (functional cysts) lesions, $37(18.7 \%)$ benign neoplastic lesions and $11(5.5 \%)$ malignant tumors. Corpus luteal cyst was the most commonly encountered ovarian functional cyst constituting 63 cases $(42.2 \%)$. This was followed by follicular cyst 42 cases $(28.1 \%)$. The peaks age incidence for non-neoplastic is 3rd decade.

Conclusion: Functional ovarian cysts were the most commonly encountered ovarian lesions in our rural area. The most common variety of functional cyst was corpus luteal cyst and follicular cyst with majority occurring in the reproductive age groups.
\end{abstract}

Keywords: Ovarian lesions, Functional cysts, Corpus luteal cysts, Follicular cyst.

\section{Introduction}

Cystic lesions of ovary are the commonly occurring gynaecological pathology. Functional and pathological cysts in the ovary typically presents as mass lesions. Functional lesions are mainly cystic and are the most commonly encountered lesions of this retroperitoneal organ. ${ }^{1}$ Functional cyst consist of mainly follicular and corpus luteal cysts. Studies have shown that $90 \%$ of these cysts are resolved spontaneously. ${ }^{2}$ surgical intervention is mandated only when these cyst develop secondary complications like torsion, progressive pain or large mass per abdomen. ${ }^{3}$

These cyst are frequently seen in young female in their $2^{\text {nd }}$ and $3^{\text {rd }}$ decades due to failure of ovulation. However, fewer cases could also be seen in perimenopausal and postmenopausal women. ${ }^{2,4}$ However it is obligatory to discriminate between functional and pathological ovarian lesions. Greater numbers of these lesions are benign in nature. Across the globe ovarian cancers comprise about $23 \%$ of overall gynaecological malignancies and 3\% of entire neoplasms in females. It is considered as the fifth common cause of cancer mortality in women., ${ }^{5,6}$ The present study is aimed at evaluating the histopathological spectrum of ovarian cystic lesions with special emphasis on functional ovarian cysts.

\section{Materials and Methods}

The study is retrospective observational study carried out in a tertiary care hospital at Shri Sathya Sai Medical College and Research Institute over a period of four years from January 2012 to December 2015.
During this period we came across 197 cases of ovarian cystic masses. All ovarian biopsies received during this period were included. All specimens sent for histopathological examinations were fixed in $10 \%$ formalin solution and processed by automated tissue processor. From the each paraffin blocks 3-5 microns sections were obtained and stained with routine hematoxylin and eosin stains. Special stains such as reticulin and periodic acid-Schiff stains were used where ever necessary. The results obtained were analyzed.

Inclusion Criteria: All ovarian biopsies with cystic presentation (inclusive of any procedure done for oophorectomy alone or with other specimens)

Exclusion Criteria: Oophorectomy specimens with normal ovarian histology. Ovarian Solid lesions/Malignancy with solid presentation.

Statistical Analysis: Data obtained were analyzed using the Statistical Package for Social Sciences (SPSS) version 21 statistical package.

\section{Results}

A total of 197 ovarian biopsies were reviewed. Out of which, $149(75.6 \%)$ of nonneoplastic (functional cysts) lesions, $37(18.7 \%)$ were benign neoplastic tumors and $11(5.5 \%)$ were malignant tumors. Among the 149 nonneoplastic lesions, corpus luteal cyst was the most commonly encountered lesions constituting about $42.2 \% \quad(n=63$, followed by follicular cyst comprising about $28.1 \% \quad(n=42)$. Others include hemorrhagic cyst and endometriotic cyst constituting about $16.7 \% \quad(\mathrm{n}=25)$ and $6.04 \%(\mathrm{n}=9)$ respectively. 
Other less common nonneoplastic lesions were paraovarian cyst $4.69 \%(n=7)$ and cortical cyst $1.3 \%$ $(n=2)$, while polycystic disease accounted for one case
(0.6\%). Among the ovarian neoplastic lesions benign lesions accounts for 37 cases $(18.7 \%)$ and malignant neoplasm accounts for 11 cases $(5.5 \%)$ See Table 1 .

Table 1: Frequency and pattern of ovarian cyst

\begin{tabular}{|l|c|c|}
\hline \multicolumn{1}{|c|}{ Pattern } & Frequency & Percentage \\
\hline Functional & \multicolumn{2}{|c|}{} \\
\hline Corpus luteal cyst & 63 & 42.2 \\
\hline Follicular cyst & 42 & 28.1 \\
\hline Hemorrhagic cyst & 25 & 16.7 \\
\hline Endometriotic cyst & 9 & 6.04 \\
\hline Paraovarian cyst & 7 & 4.69 \\
\hline Cortical cyst & 2 & 1.3 \\
\hline Polycystic cyst & 1 & 0.6 \\
\hline Neoplastic & 37 & 18.8 \\
\hline Benign Neoplasm & 37 & 5.5 \\
\hline Malignant Neoplasm & 11 &
\end{tabular}

Table 2 has illustrated that the 21-30 years was the peak age incidence for nonneoplastic ovarian cysts accounting for 76 cases $(51.00 \%)$. The 4 th decade was the 2nd most common age distribution for functional cyst accounting for 55 cases $(36.91 \%)$ respectively.
Among the neoplasms, benign neoplastic lesions showed increased percentage in the $4^{\text {th }}$ deacde $(n=26$; $70.27 \%$ ), respectively. The peak age 51-60 years were noted for malignant tumors accounting for 5 cases $(45.45 \%)$ a piece out of the 11 cases

Table 2: Age distribution and pattern of ovarian cyst

\begin{tabular}{|c|c|c|c|c|c|}
\hline Category & \multicolumn{5}{|c|}{ Age } \\
\hline Functional & 21-30 & $31-40$ & 41-50 & $51-60$ & 61-70 \\
\hline Corpus luteal cyst & 39 & 17 & 7 & - & - \\
\hline Follicular cyst & 22 & 20 & - & - & - \\
\hline Hemorrhagic cyst & 11 & 10 & 4 & - & - \\
\hline Endometriotic cyst & 3 & 5 & 1 & - & - \\
\hline Paraovarian cyst & 1 & 1 & & & \\
\hline Cortical cyst & - & 1 & 1 & & \\
\hline Polycystic cyst & - & 1 & - & - & - \\
\hline \multicolumn{6}{|l|}{ Neoplastic } \\
\hline Benign Neoplasm & 2 & 26 & 5 & 4 & \\
\hline Malignant Neoplasm & - & - & 3 & 5 & 3 \\
\hline
\end{tabular}

Table 3 depicts surface epithelial tumours shows high ncidence as ovarian cystic lesions either benign eoplasm or as malignant neoplasm.

Table 3: Distribution of Ovarian cystic neoplasms

\begin{tabular}{|l|c|c|}
\hline & Benign & Malignant \\
\hline $\begin{array}{l}\text { Surface epithelial } \\
\text { tumours }\end{array}$ & $31(64.58 \%)$ & $9(18.75)$ \\
\hline Germ cell tumours & $6(10.42 \%)$ & $1(2.08 \%)$ \\
\hline $\begin{array}{l}\text { Sex cord-Stromal } \\
\text { Tumour }\end{array}$ & $1(2.08 \%)$ & - \\
\hline
\end{tabular}

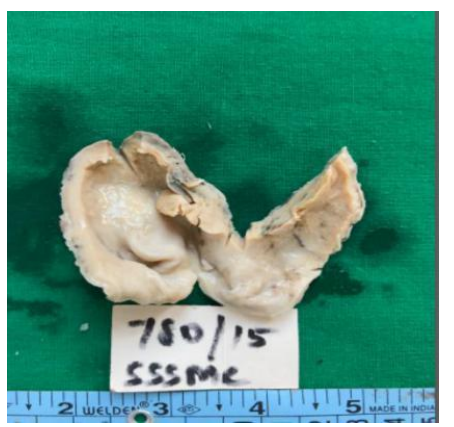

Fig. 1: Shows cut-section of ovary with unilocular thick walled cyst, light yellowish in colour and glistening surface 


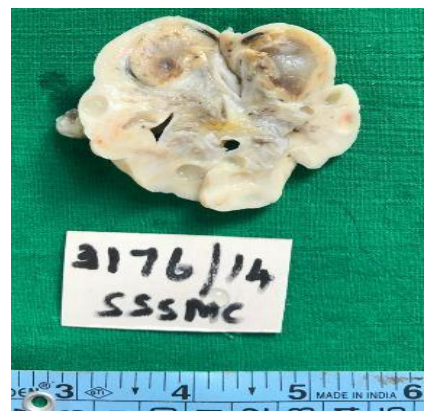

Fig. 2: Shows cut-section of ovary with cystic corpus luteum measuring $1 \times 0.8 \mathrm{~cm}$ and many follicular cyst each measuring $0.5 \times 0.3 \mathrm{~cm}$

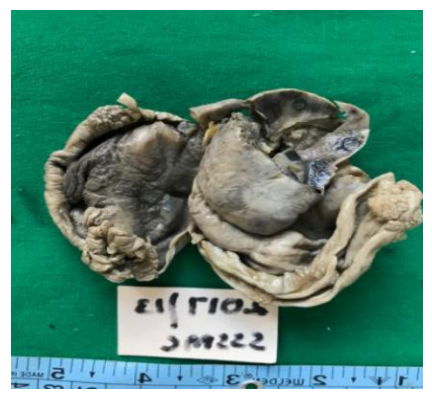

Fig.3: Shows cut-section of ovary with papillary projections on the outer surface and protruding into the cystic cavity. Other area shows brownish to blackish in colour

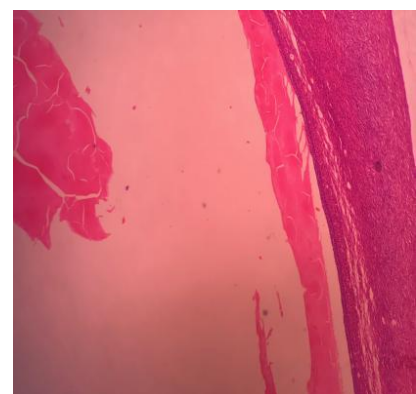

Fig. 4: Microscopically shows outer layer of theca interna cells and variable inner layer of granulosa cells

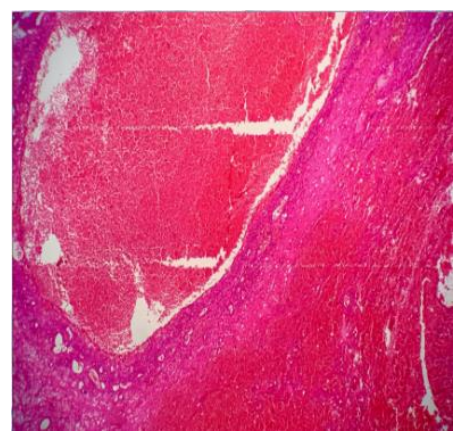

Fig. 5: Microscopically shows a cyst composed of luteinized granulosa cells and filled with hemorrhage

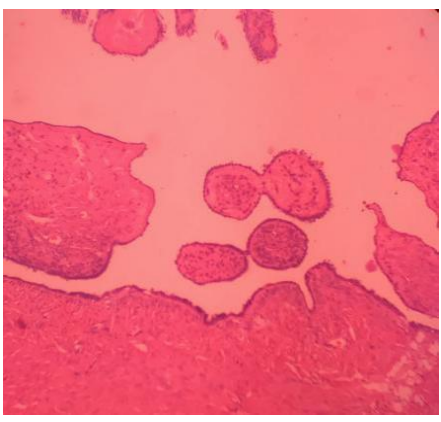

Fig. 6: Microscopically shows cysts lined by a single layer of tall, columnar ciliated epithelium. Stroma contains spindly fibroblasts without atypia and architectural complexity

\section{Discussion}

The study showed that the non-neoplastic ovarian lesions were more frequent when compared to neoplastic lesions, among non-neoplastic lesions broad majority were functional cysts. This finding is similar to the studies done by Maliheh et al..$^{7-9}$ and in contrast to the study done by Ashraf et al ${ }^{10}$ which revealed that benign neoplastic tumors were the frequently occurring ovarian lesions. Other similar studies Guerriero et $\mathrm{al}^{9}$ demonstrated that endometroma was the commonest lesion succeeded by the functional cysts. De Kroon et al ${ }^{11}$ study depicted that dermoid cyst was the second frequent lesion in the ovary.

The distribution of the functional ovarian cysts are compared with other similar studies, current study pointed out that corpus luteal cysts together with hemorrhagic corpus luteal cysts were the commonest lesions confronted followed by follicular cysts. These findings were similar to the studies done by Choi and Kim. ${ }^{12}$ In this study, the peak age incidence of nonneoplastic and benign neoplastic lesions was seen in the $3^{\text {rd }}$ and 4 th decade. These observations were concordance with other studies which revealed that vast majority of the benign ovarian lesions occur in reproductive age groups. ${ }^{1,13}$

In our study, ovarian malignancies were seen after fourth decade majority (45.45\%) of these lesions occurred between $5^{\text {th }}$ to $6^{\text {th }}$ decade. Study done by Quirk JT et al ${ }^{14}$ showed greater number of malignancies were seen in elderly postmenopausal women, our findings were in agreement with this study. It is conventionally accepted that epithelial tumours were the most common lesion seen globally. Pilli et al., committed in their study that surface epithelial tumors of ovary added up to $70.9 \%$ of overall ovarian neoplasm, this was pursued by germ cell tumors accounting to $21.2 \% .{ }^{15}$ These findings were on par with the current study which showed $83.33 \%(\mathrm{n}=40)$ were epithelial tumours and $14.58 \%(n=7)$ were germ cell tumours.

Unilocular simple ovarian cysts are usually functional ovarian cysts and resolve spontaneously. Therapy by 3 to 6 months of oral contraceptives, 
usually resolves them and this also helps to distinguish between physiological and pathological ovarian cysts. Benign ovarian tumors exhibit a wide range of clinical and histopathological patterns. Ovarian cancer has emerged as one of the commonest malignancy affecting women in India. Histomorphological study of ovarian lesions is still a gold standard method for and these observations and results prove to be valuable baseline information regarding distribution and pattern of ovarian lesions

\section{Conclusion}

From this study we conclude that functional ovarian cysts were commonest ovarian lesions. Benign ovarian cysts were common when compared to malignant ovarian neoplasms. Among the ovarian neoplasms, majority were epithelial tumours. Benign ovarian neoplasms were seen similarly in both reproductive and postmenopausal age groups. Malignant tumors were mostly in the postmenopausal group. Ovarian cancers are called "silent killer" $\&$ in most of the primary ovarian lesions they remain asymptomatic until the advanced stage. Timely diagnosis, screening, appropriate management is the pressing need today.

\section{Limitations}

Few limitations regarding this study were this is a single institute limited sample study, hence the results of this study cannot be generalized. Taking this study as reference point, future multicentric research with larger sample size involving higher number of postmenopausal cases can be planned.

\section{Conflict of Interest: None}

\section{References}

1. Kayastha S. Study of ovarian tumours in Nepal medical college Teaching Hospital. Nepal Med Coll J 2009;11:200-2.

2. Warner BW, Kuhn JC, Bar LL. Conservative management of large ovarian cysts in children: The value of serial pelvic ultrasonography. Surg 1992;112:749-55.
3. Grimes DA, Jones LB, Lopez LM, Schulz KF. Oral contraceptives for functional ovarian cysts. Cochrane Database Syst Rev 2014;4

4. Choudry A, Bangash N, Malik A, Choudry H. Adolescent ovarian tumours: A Clinico-pathological review of 15 cases. J Ayub Med Coll Abottabad 2008;20:18-21.

5. Merino MJ, Jaffe G. Age contrast in ovarian malignancy pathology. Cancer 1993;15:537-44.

6. Malik IA. A prospective study of clinic-pathological features of epithelial ovarian cancer in Pakistan. $J$ Pak Med Assoc 2002;52:155-58.

7. Wasim T, Majrroh A, Saddiq S. Comparison of clinical presentation of benign and malignant ovarian tumours. J Pak Med Assoc 2009;59:18-21.

8. Maliheh A, Mohammed H, Nadereh M, Mehdi Y, Fazareh G, Mojgan E. Surgical histopathology of benign ovarian cysts: A multicentre study. Iran J Pathol 2010;5:132-6.

9. Guerriero S, Alcazar JL, Pascual MA, Ajossa S, Gerado M, Bargellini R. Diagnosis of the most frequent benign ovarian cysts: Is ultrasonography accurate and reproducible? J Womens Health (Larchmt) 2009;18:519-27.

10. Ashraf A, Shaikh AS, Ishfaq A, Akram A, Kamal F, Ahmad N, et al. The relative frequency and histopathological patterns of ovarian masses. Biomed 2012;28:98-102.

11. de Kroon CD, van der Sandt HA, van Houwelingen JC, Jansen FW. Sonographic assessment of non-malignant ovarian cysts: Does sonohistology exist? Hum Reprod 2004;19:2138-43.

12. Choi HJ, Kim SH, Kim SH, Kim HC, Park CM, Lee HJ, et al. Ruptured corpus luteal cysts: CT Findings. Korean J Radiol 2003;4:42-5.

13. Mendal SK, Banyopadhyay R, Nag DR, Roychowdhury S, Mondal PK, Sinha SK, et al. Histologic pattern, bilaterality and clinical evaluation of 957 ovarian neoplasms: A 10-year study of a tertiary hospital of eastern India. J Cancer Res Ther 2011;7:433-37.

14. Quirk JT, Natarajan N. Ovarian cancer incidence in the United States, 1992-1999. Gynaecol Oncol 2005;97:519-23.

15. Pilli GS, Suneeta KP, Dhaded AV, Yenni VV. Ovarian tumours: A study of 282 cases. J Indian Med Assoc 200.

How to cite the article: Khan D.M, Abilash S.C, Ravathisheree R, Haritha R.S. Histopathological spectrum of ovarian cyst in our rural area. Arch Cytol Histopathol Res 2018;3(4):210-213. 